\title{
Article \\ Multi-Objective Parameter Optimization of Flexible Support System of Optical Mirror
}

\author{
Zujin Jin $^{1}\left(\mathbb{D}\right.$, Gang Cheng ${ }^{1,2, *}$, Yusong Pang ${ }^{3}\left(\mathbb{D}\right.$, Shichang $\mathrm{Xu}^{1}$ and Dunpeng Yuan ${ }^{1} \mathbb{C}$ \\ 1 School of Mechatronic Engineering, China University of Mining and Technology, Xuzhou 221116, China \\ jinzjcam@cumt.edu.cn (Z.J.); TB19050022B2@cumt.edu.cn (S.X.); TS19050040A31LD@cumt.edu.cn (D.Y.) \\ 2 Shangdong Zhongheng Optoelectronic Technology Co., Ltd., Zaozhuang 277000, China \\ 3 Faculty Mechanical, Maritime and Materials Engineering, Delft University of Technology, \\ 2628 Delft, The Netherlands; Y.Pang@tudelft.nl \\ * Correspondence: chg@cumt.edu.cn; Tel.: +86-132-2523-2379
}

check for updates

Citation: Jin, Z.; Cheng, G.; Pang, Y.; Xu, S.; Yuan, D. Multi-Objective Parameter Optimization of Flexible Support System of Optical Mirror. Appl. Sci. 2021, 11, 8071. https:// doi.org/10.3390/app11178071

Academic Editors: Jacopo Catani and Andrea Paglietti

Received: 14 July 2021

Accepted: 27 August 2021

Published: 31 August 2021

Publisher's Note: MDPI stays neutral with regard to jurisdictional claims in published maps and institutional affiliations.

Copyright: (c) 2021 by the authors. Licensee MDPI, Basel, Switzerland. This article is an open access article distributed under the terms and conditions of the Creative Commons Attribution (CC BY) license (https:// creativecommons.org/licenses/by/ $4.0 /)$
Featured Application: In this study, the main components of the flexible support system (FSS) are optimized for multi-objective parameters using the finite element method, to reduce the internal resistance of the FSS and improve the consistency of force output. The hardness of rolling diaphragm (RD) is determined by the pressure test of the FSS. The actual resistance of the support cylinder at each movement position is determined by the internal resistance test, and the consistency of the value of each support cylinder is determined by the force output consistency test. It provides a theoretical basis for the application of the FSS in the optical mirror processing stage.

Abstract: During the processing of an optical mirror, the performance parameters of the bottom support system would affect the surface forming accuracy of the mirror. The traditional bottom support system has a large unadjustable support stiffness, which increases the difficulty of unloading the impact force generated by the grinding disc. In response to this scenario, a flexible support system (FSS) consisting of 36 support cylinders with beryllium bronze reeds (BBRs) and rolling diaphragms (RDs) as key components is designed. It is necessary to analyze the key components of the support cylinder to reduce its axial movement resistance, ensure a consistent force output of each support point. First, the internal resistance model of a flexible support cylinder is established, and the main factors of internal resistance are then analyzed. Thereafter, the multi-objective structural parameters of the BBR and RD are simulated in ANSYS using the control variable method. The optimal structural parameters of BBR and RD are determined by simulation. Finally, experiments are performed on the RD ultimate pressure, internal resistance of the support cylinder, and consistency of the force output of the FSS. The experimental results show that the support cylinder with the optimized design has good force output consistency, which provides a theoretical basis for the application of FSS in optical mirror processing.

Keywords: optical mirror processing; flexible support system; beryllium bronze reed; rolling diaphragm; resistance to movement; multi-objective parameters optimization

\section{Introduction}

With the development of information technology, modern optical mirrors are being enhanced rapidly toward large apertures and high precision [1,2]. The increase in the requirements with regard to optical mirror aperture and precision has increased the difficulty of processing, as well as the requirements for processing equipment [3,4]. At present, the processing of large optical mirrors depends mainly on robots and computer numerical control (CNC) machine tools. Manual grinding is rarely used [5,6]. Furthermore, the optical mirror support systems used in processing are mostly traditional base supports, mechanical Whiffletree mechanism support systems, or hydraulic support systems [7]. Although these can meet the rigidity requirements of optical mirror processing, the rigidity 
cannot be adjusted. If the impact force of the polishing disc on the surface of an optical mirror being processed is excessive, it may damage the surface. This is particularly so for large, lightweight thin mirrors. The force may crush the mirror surface, and thereby, result in the consumption of a substantial amount of manpower and material resources [8-10]. Therefore, the performance parameters of the bottom support system are crucial for ensuring the surface forming accuracy of optical mirrors, in addition to the improvement of the motion accuracy of robot and machine tool [11,12].

In recent years, many scholars have conducted a substantial amount of research on the support methods used in optical mirror processing, installation and posture adjustments. In addition, a few scholars optimized the structural parameters of support systems. Zhou et al. developed an active optics system based on a passive and whiffletree-supported mirror to compensate for the gravity-induced deformation and correct low-order aberrations caused by thermal variations and gravity relief during observing periods [13]. To counteract the effect of gravity deformations on the mirror surface of a space telescope's main mirror during installation, Kihm et al. improved the support system by using a flexure device with mechanical spacers instead of the traditional bipod flexure device [14]. To realize an ultra-light design of large-caliber splicing mirrors, Liu et al. proposed a mirror support and drive integrated design method, combined with optical precision and surface accuracy of mirrors and position adjustment [15]. It was based on an analysis of the existing design schemes. Yang et al. proposed a design scheme using carbon fiber-reinforced plastic truss rods for passive thermal compensation to improve the thermal effect of telescopes [16]. In addition, the function of thermal expansion coefficient and truss rod length was determined according to the principle of equal axial distance after deformation. Bi et al. used a flexible mechanism with a cross spring pivot, in the fields of precision engineering and aerospace, and established its precise load rotation and center displacement model [17]. Wei et al. applied the truss support structure to a space camera. They optimized the truss structure size through the weighting method to ensure good dynamic and static performance by large-area, off-axis three-mirror anastigmat space cameras [18]. Many of these scholars also use flexible support system (FSS) in the field of optical mirror support. To improve the fabrication efficiency and testing accuracy of meter-scale, Hu et al. designed and manufactured a few hydraulic support units and tested these through a $4 \mathrm{~m} \mathrm{SiC} \mathrm{mirror} \mathrm{[19].}$ Therefore, the high accuracy of the designed support system was established. In order release the thermal stress of the optical primary mirror, Huo et al. proposed a novel kinematic flexure mount, composed of three identical chains and analyzed the stiffness characteristics of its structure [20]. Yan et al. proposed a multi-point flexible unit and a four-point length adjustable radial lens support structure to support and position a lens assembly with large aperture and high precision in an on-orbit assembly space telescope validation prototype [21]. Yu et al. designed a new type of three-leaf flexible structure based on the spring principle and optimized the size parameters of the flexible structure through the finite element analysis method [22]. Dai et al. used floating support for a $1.2 \mathrm{~m}$ thin mirror support and proposed a new floating support force distribution algorithm [23]. To achieve an accurate surface form and optical axis stability of a large aperture lens in a ground-based telescope system subject to various load cases, Zhang et al., proposed a novel lens support with a multi-point flexible support structure and based on low-order modes and system accuracy to optimize its supporting structure [24]. Wang et al. designed a tangential flexible support structure and an axial flexible support structure to compensate for temperature and gravity load disturbances on a large-aperture optical mirror [25]. The above-mentioned scholars have carried out a substantial amount of research on the support systems of optical mirrors. They used the support systems for the installation, positioning, and detection of large-diameter or thin mirrors, by improving traditional mechanisms, designing new support systems, and optimizing mechanism parameters of the support systems. However, few scholars use the support system in the optical mirror processing stage. This is particularly so with regard to the application of the FSS in the processing of large-scale optical mirrors, which is deficient in terms of relevant theoretical foundation. In 
engineering applications, a few scholars have successfully applied FSS to the processing of thin-walled parts, such as aircraft skins $[26,27]$. Therefore, it is necessary to further study the application of the FSS in the processing stage of large-aperture optical mirrors.

An FSS with adjustable rigidity is designed to enable the adjustment of the rigidity of the bottom support system of a large-scale optical mirror during processing and to effectively unload the impact force generated by the grinding disc. In addition, the main components of the FSS are optimized for multi-objective parameters using the finite element method, in order to reduce the internal resistance of the FSS and improve the consistency of force output. In Chapter 2, the motion resistance modeling of FSS and support cylinder are carried out, and the target parameters to be optimized are determined. In Chapter 3, through the multi-objective optimization analysis, the optimal target parameters of beryllium bronze reed and rolling diaphragm are determined. In Chapter 4, the performance of the optimized support system is verified by experiments. In Chapter 5 , the conclusion of this paper is drawn.

\section{Modeling of Motion Resistance}

\subsection{Motion Resistance Modeling of FSS}

As shown in Figure 1, the FSS consists of 36 support cylinders and is divided into three sectors on average. The upper and lower chambers of the cylinders in each sector are connected through hydraulic lines, which ensures equal pressure in the upper and lower chambers in the same sector. The rigidity of the support cylinder can be adjusted by varying the pressure values of the upper and lower chambers, and the support height of the cylinder can be adjusted by varying the pressure difference between these chambers. Therefore, the posture of the optical mirror can be fine-adjusted by varying the support parameters of the cylinders in the three sectors. The internal resistance of the support cylinder would affect the force output consistency and support stiffness of the FSS. The main components that cause the internal resistance of the support cylinder are the beryllium bronze reed (BBR) and rolling diaphragm (RD). The structural parameters of the BBR and RD need to be optimized and analyzed to reduce the internal resistance of the FSS.

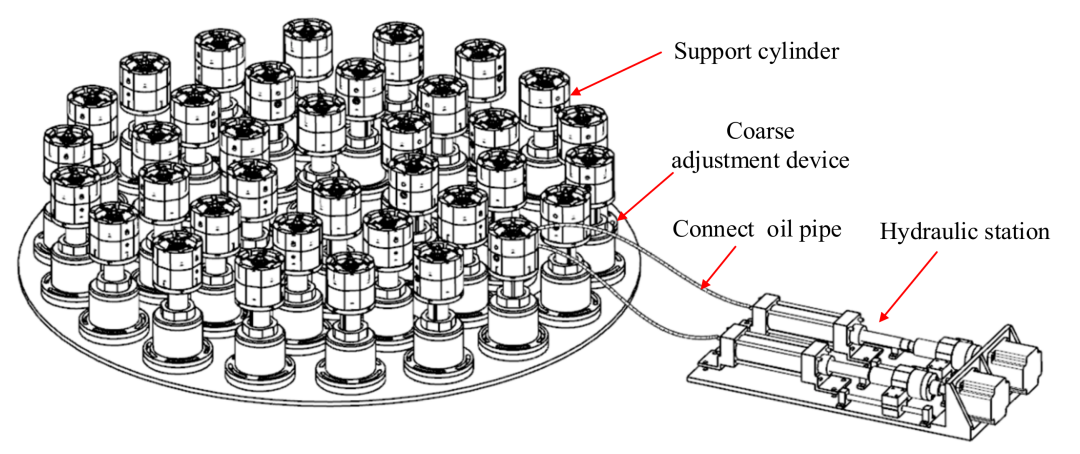

Figure 1. Topology of the flexible support system.

The structure of the support cylinder is shown in Figure 2. There is no direct contact between the piston and cylinder, and the BBR is used for radial support to prevent frictional resistance between the piston and cylinder wall during movement. The small RDs of the upper and lower chambers isolate these chambers from air, and the large RDs separate these chambers. Therefore, two closed spaces are formed. When the support cylinder moves, the BBR and RD would deform elastically, and thereby cause the support cylinder to generate internal resistance. 


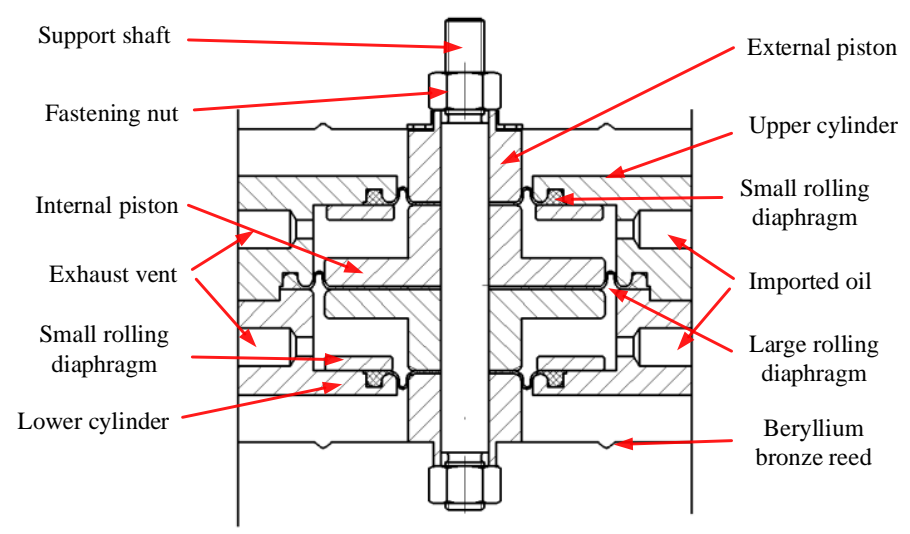

Figure 2. Schematic diagram of support cylinder.

Because the FSS is composed of three separate liquid supply sectors (which do not interfere with each other), the internal resistance of the FSS can be divided into three components:

$$
F_{\text {toatl }}=\left[\begin{array}{lll}
F_{a} & F_{b} & F_{c}
\end{array}\right]^{T}
$$

where $F_{a}, F_{b}$, and $F_{c}$ are the internal resistances of Components 1,2 , and 3, respectively.

$$
\left[\begin{array}{c}
F_{a} \\
F_{b} \\
F_{c}
\end{array}\right]=\left[\begin{array}{ccccccccccccccc}
H_{1}^{1} & \cdots & H_{1}^{12} & H_{2}^{1} & \cdots & H_{2}^{12} & P_{1}^{1} & \cdots & P_{1}^{12} & P_{2}^{1} & \cdots & P_{2}^{12} & P_{3}^{1} & \cdots & P_{3}^{12} \\
H_{1}^{13} & \cdots & H_{1}^{24} & H_{2}^{13} & \cdots & H_{2}^{24} & P_{1}^{13} & \cdots & P_{1}^{24} & P_{2}^{13} & \cdots & P_{2}^{24} & P_{3}^{13} & \cdots & P_{3}^{14} \\
H_{1}^{25} & \cdots & H_{1}^{36} & H_{2}^{25} & \cdots & H_{2}^{36} & P_{1}^{25} & \cdots & P_{1}^{36} & P_{2}^{25} & \cdots & P_{2}^{36} & P_{3}^{25} & \cdots & P_{3}^{36}
\end{array}\right]
$$

where 1-36 are the numbers representing the support cylinders; $H_{1}$ and $H_{2}$ are the internal resistances caused by the elastic deformation of the BBRs in the upper and lower chambers, respectively, of the support cylinder; and $P_{1}, P_{2}$, and $P_{3}$ are the internal resistances caused by the elastic deformation of the upper chamber RD, lower chamber RD, and middle $\mathrm{RD}$, respectively.

\subsection{Internal Resistance Modeling of Single Cylinder}

There is no friction resistance in the support cylinder. Its internal resistance is only related to the elastic deformation of the BBR and RD. As shown in Figure 2, the deformation directions of the BBR and RD on the upper and lower chambers are different when the support cylinder moves.

$$
F=\left[\begin{array}{c}
H_{1}\left(d, w, L, h, p_{r}, p_{s}\right) \\
H_{2}\left(d, w, L, h, p_{r}, p_{s}\right) \\
P_{1}\left(R_{p}, K, D_{p 1}, W_{h 1}, W_{s w}, H_{s d}\right) \\
P_{2}\left(R_{p}, K, D_{p 1}, W_{h 1}, W_{s w}, H_{s d}\right) \\
P_{3}\left(R_{p}, K, D_{p 2}, W_{h 2}, W_{s w}, H_{s d}\right)
\end{array}\right]
$$

where $d$ is the elastic beam thickness of the BBR, $w$ is the elastic beam width of the BBR, $L$ is the effective length of the elastic beam, $h$ is the bending height, $p_{r}$ is the bending angle, $p_{s}$ is the bending position. $R_{p}$ is the radius of the piston chamfer, $K$ is the forming height of the RD, $D_{p 1}$ and $D_{p 2}$ are the installation diameters of the small and intermediate RDs, respectively; $W_{h 1}$ and $W_{h 2}$ are the thicknesses of the small and intermediate RDs, respectively; $W_{s w}$ is the side wall thickness; and $H_{s d}$ is the RD hardness. The structures of the BBR and RD are shown in Figures 3 and 4, respectively. 


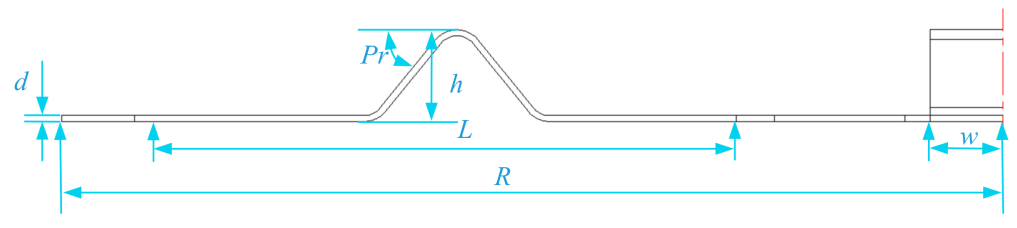

Figure 3. Structural parameters of beryllium bronze reed (BBR).

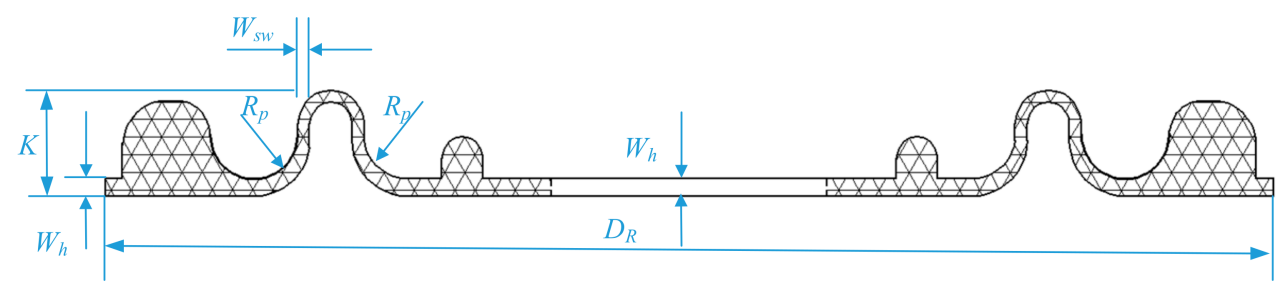

Figure 4. Structural parameters of rolling diaphragm (RD).

The movement resistance of the BBR exhibits non-linear relationships with $d, w, L$, $h, p_{r}$, and $p_{s} . w, L$, and $h$ are determined according to the design of the support cylinder, whereas $d, p_{r}$, and $p_{s}$ need to be optimized according to the performance parameters of the support cylinder.

The movement resistance of the RD exhibits non-linear relationships with $R_{p}, K, D_{p}$, $W_{h}, W_{s w}$, and $H_{s d} . R_{p}, D_{p}, W_{h}$, and $W_{s w}$ are determined according to the design of the support cylinder, and $H_{s d}$ need to be optimized according to the performance parameters of the support cylinder.

$$
K=\frac{1}{2}\left(S_{M}+C+2 R_{P}+2 W_{h}\right)
$$

where $C$ is the distance between the cylinder wall and piston. $S_{M}$ is the maximum half-stroke:

$$
S_{M}=\operatorname{Max}\left(S_{A}, S_{B}\right)
$$

where $S_{A}$ and $S_{B}$ are the upward and downward strokes, respectively.

During the operation of the support cylinder, the hydraulic oil in the upper chamber would exert a force on the small RD in the upper cavity and the middle RD, and that in the lower chamber would exert a force on the small RD in the lower chamber and the middle $\mathrm{RD}$. The RD deformations in the upper and lower chambers of the support cylinder differ owing to the pressure difference between these.

(1) The deformation of the small RD of the upper chamber is:

$$
\Delta L_{s u}=\frac{C_{1} K_{1}-C_{1} / 2}{2 E W_{h 1}} P_{u}+\frac{C_{1}^{2} P_{u}}{4 E W_{h 1}}
$$

where $C_{1}$ is the distance between the cylinder wall and external piston, $P_{u}$ is the upper chamber pressure, $K_{1}$ is the height of the small $\mathrm{RD}$, and $E$ is the elastic modulus of the RD.

(2) The deformation of the small RD of the lower chamber is:

$$
\Delta L_{s d}=\frac{C_{1} K_{1}-C_{1} / 2}{2 E W_{h 1}} P_{d}+\frac{C_{1}^{2} P_{d}}{4 E W_{h 1}}
$$

where $P_{d}$ is the lower chamber pressure.

(3) The deformation of the middle RD is:

$$
\Delta L_{b}=\frac{C_{2} K_{2}-C_{2} / 2}{2 E W_{h 2}}\left(P_{u}-P_{d}\right)+\frac{C_{2}^{2}\left(P_{u}-P_{d}\right)}{4 E W_{h 2}}
$$

where $C_{2}$ is the distance between the cylinder wall and internal piston. $K_{2}$ is the height of the large RD. 


\section{Multi-Objective Parameters Optimization Design of Support Cylinder}

The internal resistance of the support cylinder is directly related to the axial movement resistance of the BBR and RD. The parameters of the BBR and RD need to be optimized further to reduce the internal resistance of the support cylinder.

\subsection{Multi-Objective Parameters Optimization Design of BBR}

The beryllium bronze used in the experiment is QBe2. Its elastic modulus is $1.25 \times 10^{11} \mathrm{~N} / \mathrm{m}^{2}$, Poisson's ratio is 0.3 , and mass density is $8.25 \times 10^{3} \mathrm{Kg} / \mathrm{m}^{3}$. The model of the BBR is shown in Figure 5, and the main parameters are listed in Table 1.

Table 1. Structural parameters of beryllium bronze reed.

\begin{tabular}{cccc}
\hline Name & Parameter & Name & Parameter \\
\hline Elastic beam thickness & Optimization objective & Bending position & Optimization objective \\
Elastic beam width & $w=7 \mathrm{~mm}$ & Bending angle & Optimization objective \\
Effective length of elastic beam & $L=27 \mathrm{~mm}$ & Installed inner radius & $R=14 \mathrm{~mm}$ \\
Install outer radius & $R=24 \mathrm{~mm}$ & Bending height & $h=4 \mathrm{~mm}$ \\
\hline
\end{tabular}

According to the design parameters and performance of the flexible support cylinder, the requirements of BBR are as follows:

(1) When a force of $+1 \mathrm{~N}$ or $-1 \mathrm{~N}$ is applied in the Y-direction of the BBR, its displacement in this direction is $\geq 0.5 \mathrm{~mm}$ or $\leq-0.5 \mathrm{~mm}$.

(2) When the BBR moves $+1 \mathrm{~mm}$ or $-1 \mathrm{~mm}$ in the Y-direction, the applied force is $\leq 3 \mathrm{~N}$.

(3) When a force of $+10 \mathrm{~N}$ is applied in the $\mathrm{X}$-direction or $\mathrm{X}, \mathrm{Z}$ centerline direction of the $\mathrm{BBR}$, its displacement is $\leq 0.5 \mathrm{~mm}$.

(4) When the BBR moves $0.5 \mathrm{~mm}$ in the $\mathrm{X}$ direction or $\mathrm{X}, \mathrm{Z}$ centerline direction, the applied force is $\geq 50 \mathrm{~N}$.

According to the above four conditions, a model for multi-objective parameters of different elastic beam thicknesses, elastic beam bending positions, and elastic beam bending angles of the BBR is established. In ANSYS (ANSYS, Inc., ANSYS 17.0, Commonwealth, PA, USA), the four positioning holes fixed by screws on the BBR elastic beam are set as the non-deformable, and the ring with the inner ring installed on the external piston is also set as the non- deformable. In the process of applying force, the applied force is applied on the inner circular axis to simulate the stress and deformation of BBR when the support shaft actually moves.

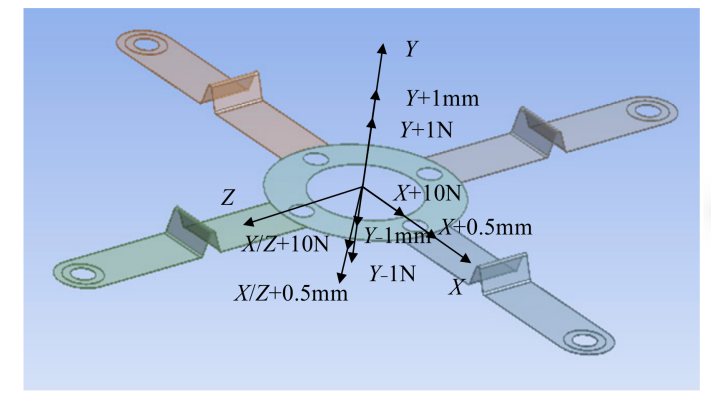

(a)

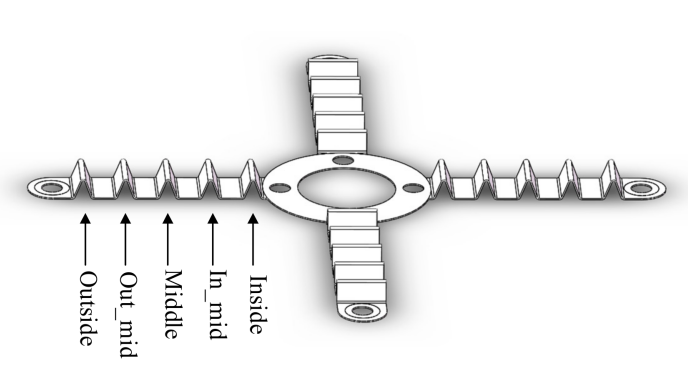

(b)

Figure 5. Simulation parameters of BBR (a) Driving direction of force and displacement. (b) Bending position.

In Figure 5a, (1) $Y+1 \mathrm{~N}$ : Apply a force of $1 \mathrm{~N}$ in the $Y$-direction to calculate the displacement of the BBR. (2) $Y-1 \mathrm{~N}$ : Apply a force of $-1 \mathrm{~N}$ in the $Y$-direction to calculate the displacement of the BBR. (3) $Y+1 \mathrm{~mm}$ : Apply a displacement of $1 \mathrm{~mm}$ in the $Y$-direction to calculate the force to be applied in this direction. (4) $Y-1 \mathrm{~mm}$ : Apply a displacement of $-1 \mathrm{~mm}$ in the $Y$-direction to calculate the force to be applied in this 
direction. (5) $X+10 \mathrm{~N}$ : Apply a force of $10 \mathrm{~N}$ in the $X$-direction to calculate the displacement of the BBR. (6) $X, Z+10 \mathrm{~N}$ : Apply a force of $10 \mathrm{~N}$ in the $X, Z$ centerline direction to calculate the displacement of the BBR. (7) $X+0.5 \mathrm{~mm}$ : Apply a displacement of $0.5 \mathrm{~mm}$ in the $X$-direction to calculate the force to be applied in this direction. (8) $X, Z+0.5 \mathrm{~mm}$ : Apply a displacement of $0.5 \mathrm{~mm}$ in the $X, Z$ centerline direction, and calculate the force to be applied in this direction.

In Figure 6, Serial numbers 1-30: the thickness of the BBR is $0.1 \mathrm{~mm}$. Serial numbers 31-60: the thickness of the BBR is $0.15 \mathrm{~mm}$. Serial numbers 31-60: the thickness of the BBR is $0.15 \mathrm{~mm}$. Serial numbers $91-120$ : the thickness of the BBR is $0.25 \mathrm{~mm}$. Serial numbers 121-150: the thickness of the BBR is $0.3 \mathrm{~mm}$.

The results of Figure $6 \mathrm{a}-\mathrm{d}$ are analyzed. It could be determined that the BBRs with thicknesses of $0.1 \mathrm{~mm}, 0.15 \mathrm{~mm}, 0.25 \mathrm{~mm}$, and $0.3 \mathrm{~mm}$ do not fully satisfy these four design requirements. The BBR with a thickness of $0.2 \mathrm{~mm}$ is analyzed further to determine the optimal bending angle and bending position. According to Figure 6, the displacements generated by applying $+1 \mathrm{~N}$ and $-1 \mathrm{~N}$ in the $Y$-direction are approximately equal. The forces required to generate displacements of $+1 \mathrm{~mm}$ and $-1 \mathrm{~mm}$ in the $Y$-direction are approximately equal. The displacements generated by applying $+10 \mathrm{~N}$ in the $Y$-direction and $X, Z$ centerline direction are approximately equal. The force required to generate a displacement of $0.5 \mathrm{~mm}$ in the $X$-direction and $X, Z$ centerline direction are approximately equal. Therefore, only the following data are analyzed; the displacement caused by the application of $1 \mathrm{~N}$ force in the $Y$-direction, force required to generate a displacement of $1 \mathrm{~mm}$ in the $Y$-direction, displacement caused by the application of $10 \mathrm{~N}$ in the $X$-direction, and force required to generate a displacement of $0.5 \mathrm{~mm}$ in the $X$-direction.

In Figure 7, Bending position 1 indicates that the bending position is in the outermost position, Bending position 2 indicates that the bending position is in the outer middle position, Bending position 3 indicates that the bending position is in the middle position, Bending position 4 indicates that the bending position is in the middle position, and Bending position 5 indicates the bending position is in the innermost position. Apply a force of $1 \mathrm{~N}$ in the $Y$-direction of the BBR with a thickness of $0.2 \mathrm{~mm}$ to calculate the displacement. It can be observed from Figure 7 that the red and blue curved surfaces are the regions with the largest, and smallest deformations, respectively. In addition, the red and orange areas with large deformation are distributed mainly in the areas where the bending position is outside, middle, and inside. In this area, the maximum deformation of the BBR in the $Y$-direction is $0.6 \mathrm{~mm}-0.65 \mathrm{~mm}$.

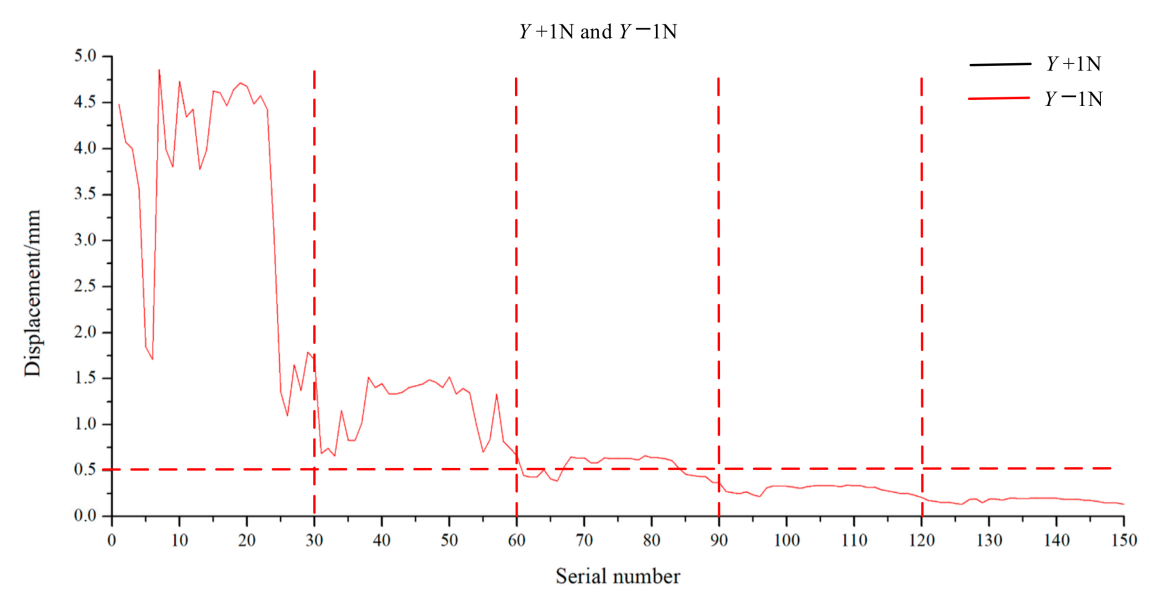

(a)

Figure 6. Cont. 


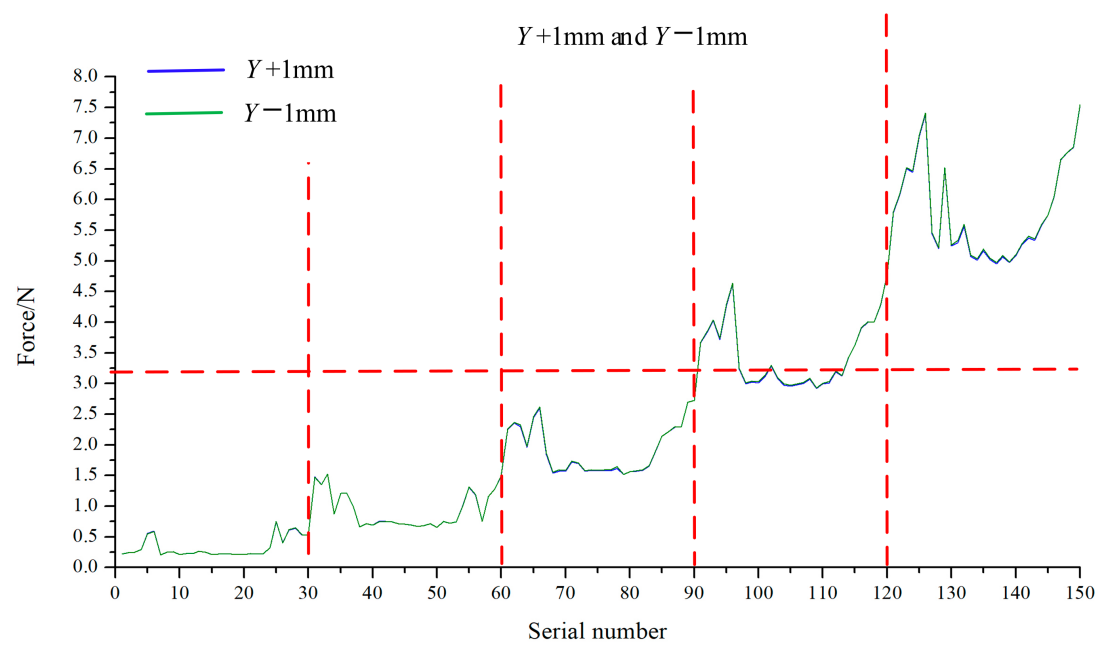

(b)

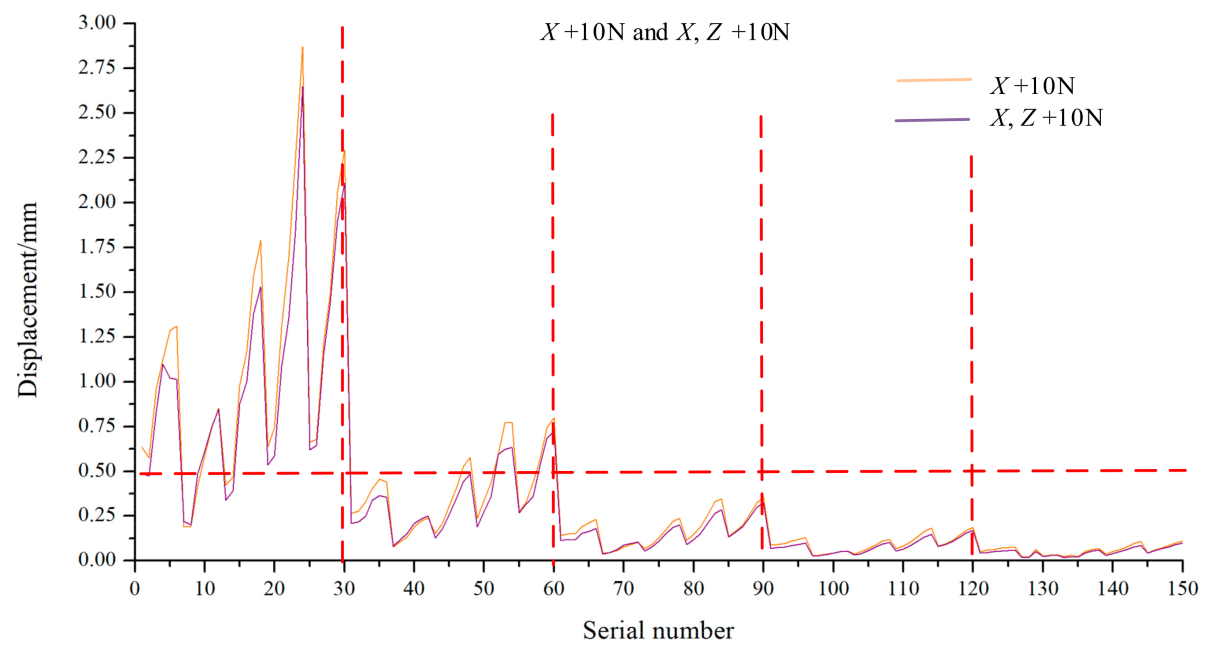

(c)

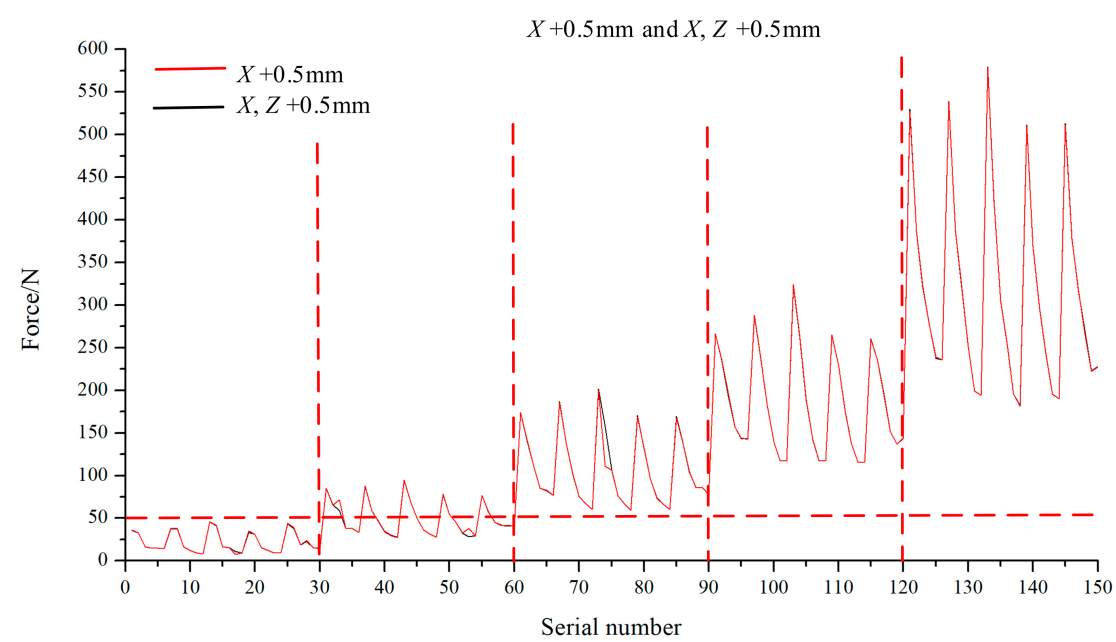

(d)

Figure 6. The data analysis of BBR. (a) $Y+1 \mathrm{~N}$ and $Y-1 \mathrm{~N}$. (b) $Y+1 \mathrm{~mm}$ and $Y-1 \mathrm{~mm}$. (c) $X+10 \mathrm{~N}$ and $X, Z+10 \mathrm{~N}$. (d) $X+0.5 \mathrm{~mm}$ and $X, Z+0.5 \mathrm{~mm}$. 


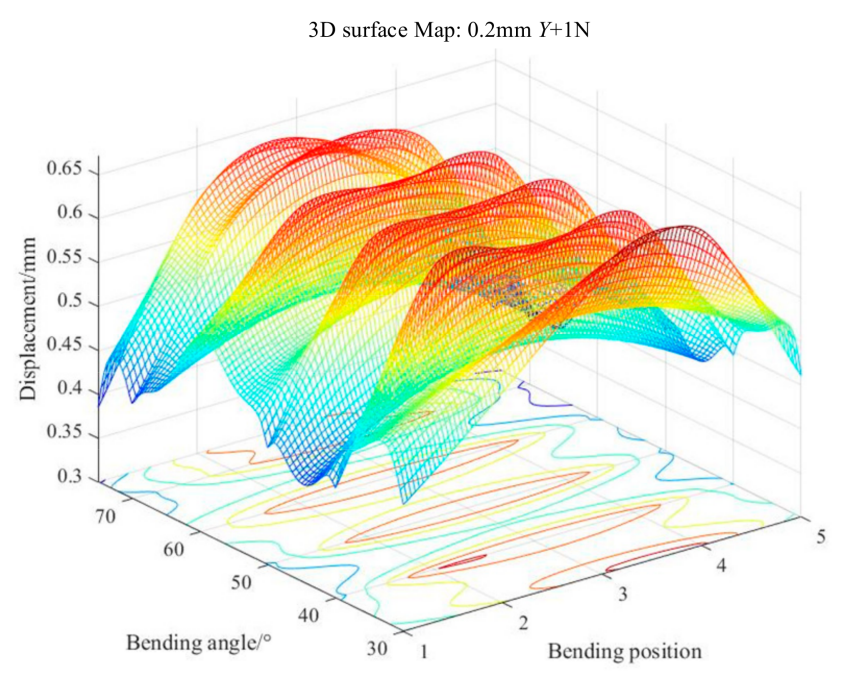

Figure 7. Displacement caused by the application of $1 \mathrm{~N}$ in the $Y$-direction.

The analysis of Figures 7-10 reveals that if a BBR with a thickness of $0.2 \mathrm{~mm}$ is expected to display lower resistance to axial deformation and larger resistance to radial deformation, the bending displacement of BBR is in the middle position and the bending angle is $30^{\circ}$. The performance parameters of the BBR in this area are as follows: (1) $Y+1 \mathrm{~N}$, the displacement of axial displacement is $0.636 \mathrm{~mm}$; (2) $Y+1 \mathrm{~mm}$, the required axial driving force is $1.566 \mathrm{~N}$; (3) $X+10 \mathrm{~N}$, the displacement of radial movement is $0.067 \mathrm{~mm}$; and (4) $X+0.5 \mathrm{~mm}$, the required radial driving force is $157 \mathrm{~N}$. These fully satisfy the four conditions required for the design of support cylinders.

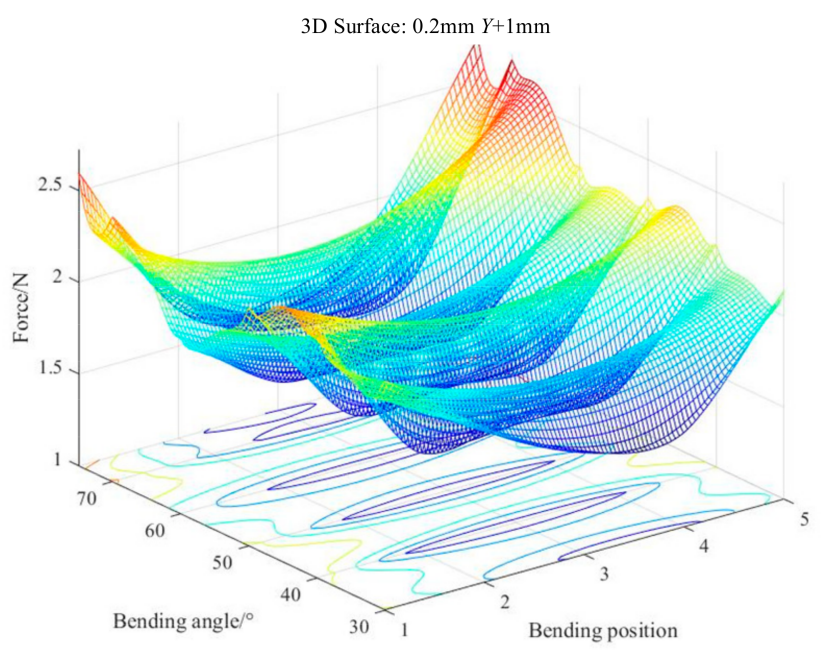

Figure 8. Driving force required to move $1 \mathrm{~mm}$ in the $Y$-direction.

Apply a force of $10 \mathrm{~N}$ in the $X$-direction of the BBR with a thickness of $0.2 \mathrm{~mm}$ to calculate the displacement. It can be observed from Figure 9 that the red and blue curved surfaces are the regions with the largest, and smallest deformations, respectively. The red and orange areas with large deformation correspond to the inner middle and innermost bending positions of the BBR, and the angle is in the range $70^{\circ}-75^{\circ}$. The blue area with the smallest deformation corresponds to the outer, outer middle, middle, inner middle, and innermost bending positions of the BBR; the angle is within the range $30^{\circ}-50^{\circ}$; and the minimum displacement is approximately $0.05 \mathrm{~mm}$. 


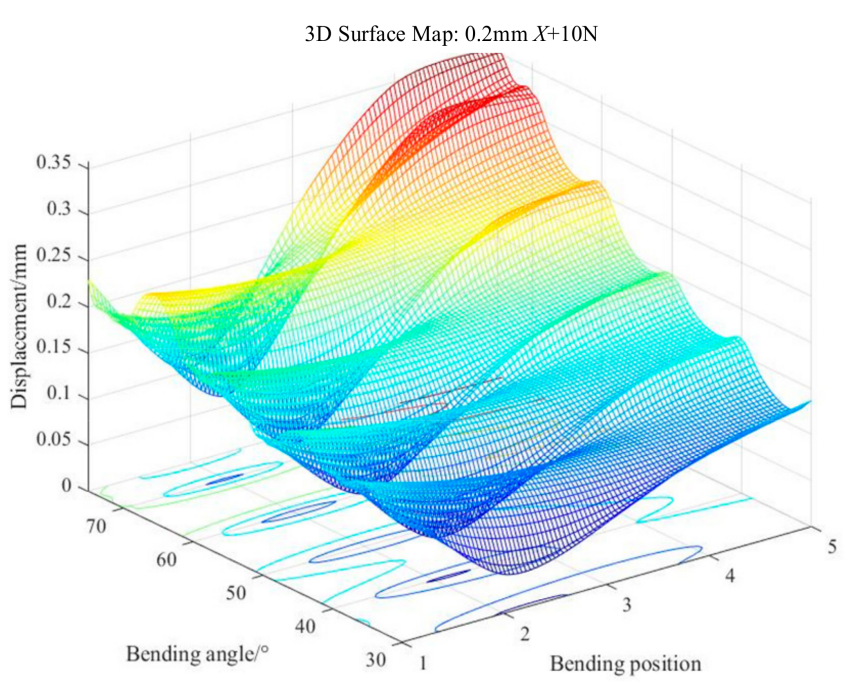

Figure 9. Displacement caused by a force of $10 \mathrm{~N}$ applied in the $X$-direction.

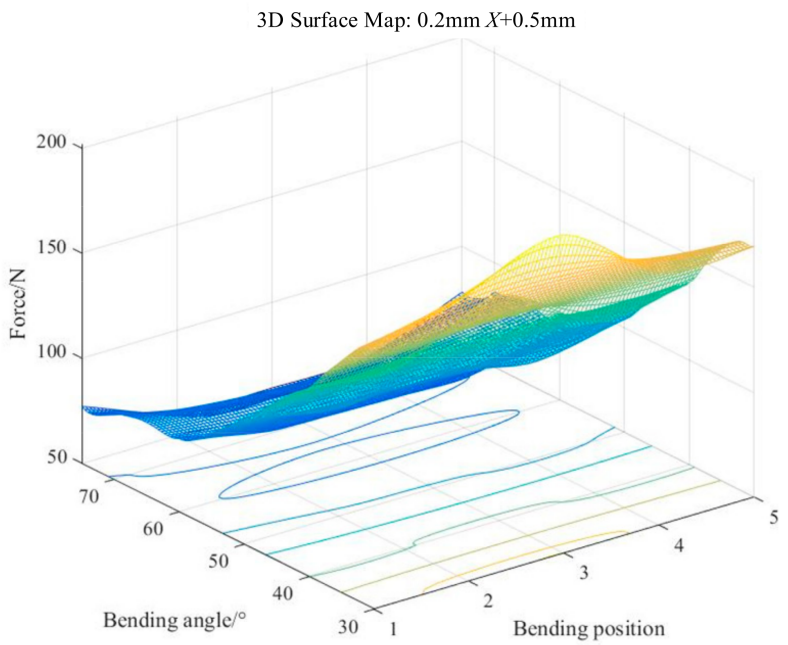

Figure 10. Force required to produce a displacement of $0.5 \mathrm{~mm}$ in the $X$-direction.

\subsection{Multi-Objective Parameters Optimization Design of RD}

The RD is made of butadiene and acrylonitrile by emulsion polymerization. It has good oil resistance, wear resistance, and heat resistance, and is suitable for the working environment of FSSs. The hardness of the RD would vary with the content and composition. In general, the hardness of RDs varies from 30 to 90 Shore. The elastic modulus of an RD varies with its hardness, and the deformation resistance generated during the movement also varies. The hardness parameters of RDs need to be optimized to maximize the performance of FSSs. As shown in Figure 11, in the simulation process, the displacement of a large and a small RD is applied in the $Y$-direction, and the driving force used by RDs with different hardness values is analyzed. Main parameters of RD, as shown in Table 2.

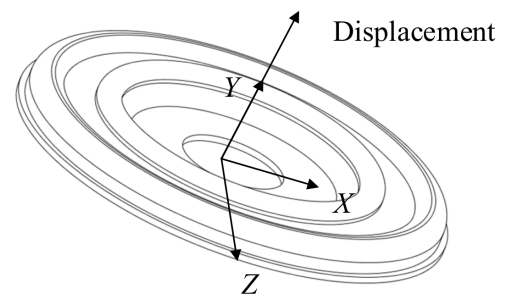

Figure 11. Driving direction of RD displacement. 
Table 2. Main parameters of rolling diaphragm.

\begin{tabular}{cccc}
\hline Name & Numerical Value & Name & Numerical Value \\
\hline Chamfer radius & $R_{p}=1.6 \mathrm{~mm}$ & RD thickness & $W_{h}=0.635 \mathrm{~mm}$ \\
Preform height & $K=3.8 \mathrm{~mm}$ & Side wall thickness & $W_{s w}=0.43 \mathrm{~mm}$ \\
Installation diameter & $D_{p 1}=42 \mathrm{~mm}$ & RD hardness & Optimization objective \\
\hline
\end{tabular}

The displacement of the support cylinder in the positive and negative $Y$-directions is $1 \mathrm{~mm}$. Therefore, in the simulation process, a displacement of $-1 \mathrm{~mm}-1 \mathrm{~mm}$ with a gradient of $0.1 \mathrm{~mm}$ is applied in the $Y$-direction of the large and small RDs with different hardness values, to calculate the movement resistance.

As can be observed from Figures 12 and 13, the required driving force is approximately equal when the RDs are of identical hardness and an equal displacement is applied in the positive and negative $Y$-directions. In addition, the motion resistance increases with the increase in material hardness and axial displacement. When the displacement is $1 \mathrm{~mm}$, the $\mathrm{RD}$ movement resistance is minimum when the hardness is 30 Shore, and the RD movement resistance is maximum when the hardness is 90 Shore. Moreover, the minimum and maximum resistance of the large $\mathrm{RD}$ is $0.32 \mathrm{~N}$, and $2.5 \mathrm{~N}$, respectively, and that of the small $\mathrm{RD}$ is $0.26 \mathrm{~N}$ and $1.96 \mathrm{~N}$, respectively. Therefore, under the requirements of working pressure, a smaller hardness of the $\mathrm{RD}$ is more effective.

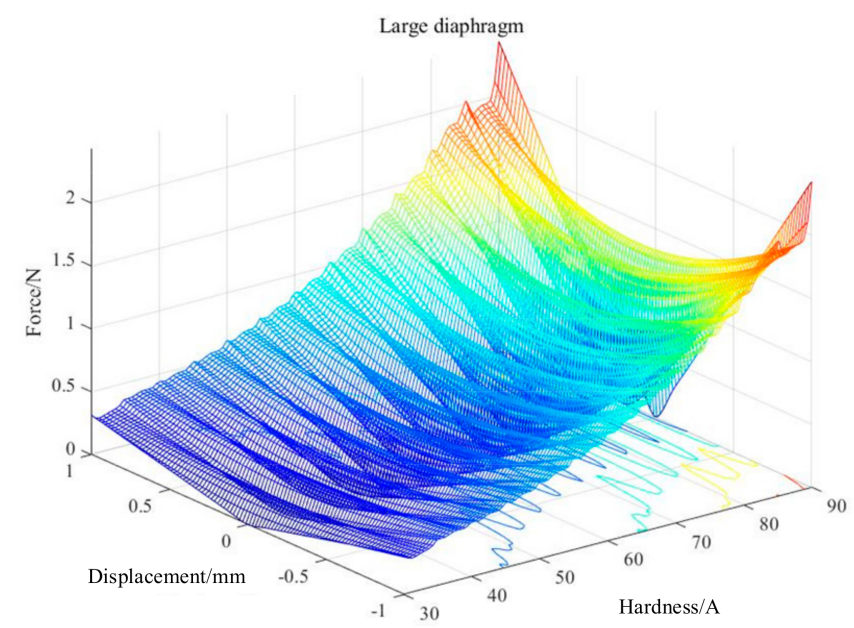

Figure 12. Movement resistance of large RD.

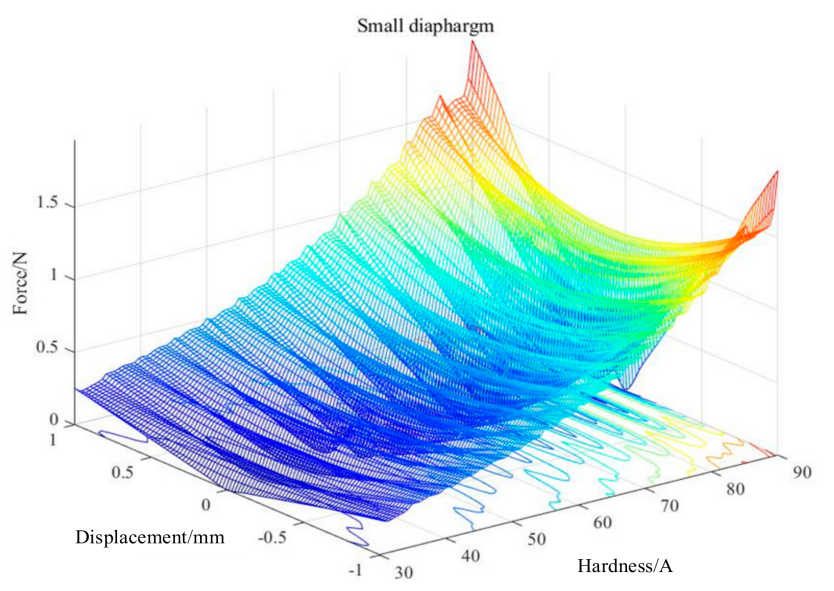

Figure 13. Movement resistance of small RD. 


\section{Experimental Analysis}

The BBR and RD obtained through the multi-objective parameter optimization analysis were installed on an FSS to verify whether these could satisfy its performance requirements. Then, the pressure test, internal resistance measurement test, and force output consistency test were carried out on the FSS. The FSS is shown in Figure 14.

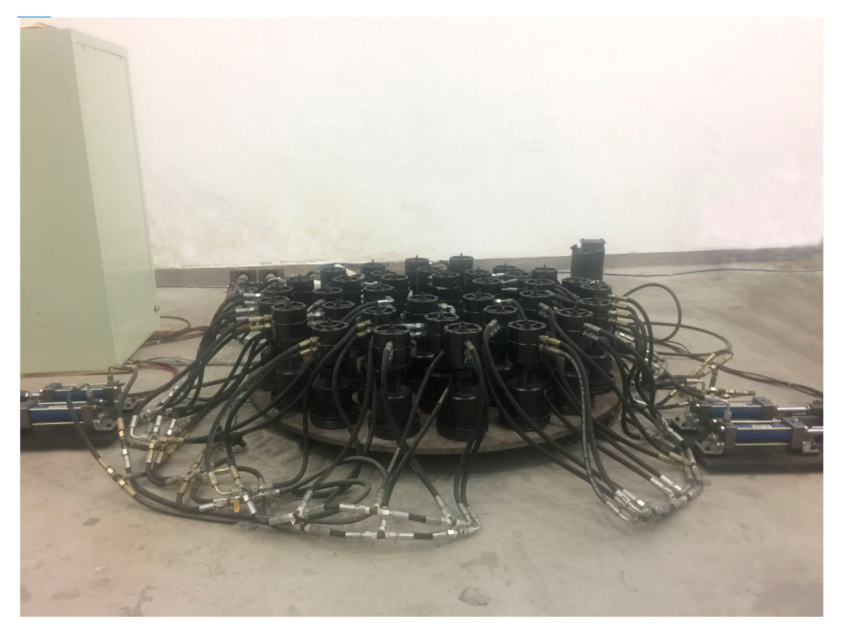

Figure 14. Experimental prototype of the Flexible support system.

\subsection{Pressure Test of FSS}

The RD determines the pressure resistance of the FSS. When the size parameters of the $\mathrm{RD}$ are determined, its hardness plays a decisive role in the rated working pressure of the FSS. In the experiment, install the RDs of different hardness values in the FSS. Then, gradually apply pressure to the upper and lower chambers of the FSS until the RD is damaged by pressure. The highest pressure is then recorded (i.e., the pressure attained when the $\mathrm{RD}$ is damaged). The ultimate pressure of the $\mathrm{RD}$ at each hardness value collected through repeated tests is shown in Figure 15.

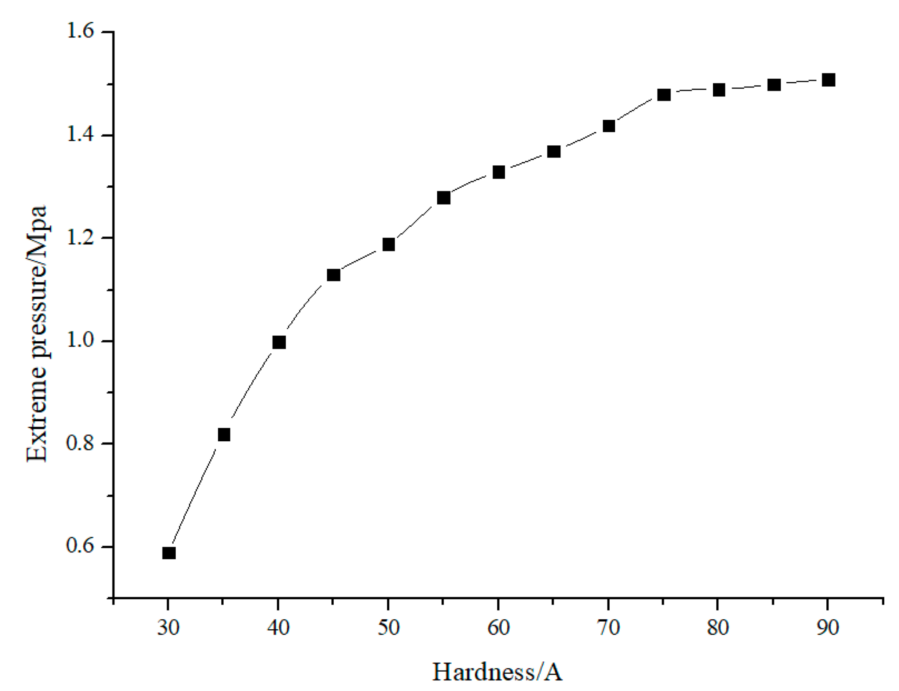

Figure 15. Relationship between RD hardness and limit working pressure.

It can be observed from Figure 15 that when the RD hardness is at least 40 Shore, the ultimate pressure that it can withstand satisfies the requirement of the rated pressure of the FSS (1 MPa). The simulation results of the RD reveal that when the RD hardness is smaller under identical structural parameters, the deformation resistance is smaller. A 45 Shore $\mathrm{RD}$ is selected for use in the FSS to minimize the deformation resistance of the RD while 
increasing its life. It can be observed from Figures 12 and 13 that, when the deformation of the RD with a hardness of 45 Shore is $1 \mathrm{~mm}$, the deformation resistance of the large and small RDs is $0.5 \mathrm{~N}$ and $0.35 \mathrm{~N}$, respectively. At this time, the ultimate pressure that the FSS can withstand is $1.18 \mathrm{MPa}$.

\subsection{Measurement Experiment of Internal Resistance of Support Cylinder}

A BBR with a thickness of $0.2 \mathrm{~mm}$, bending position in the middle, bending angle of $30^{\circ}$, and RD with hardness of 45 Shore are applied in the experiment. According to the test requirements of measuring the internal resistance of the support cylinder, the test bench is shown in Figure 16. The support cylinder is placed horizontally on the test-bed, and the radial resistance of BBR is balanced with the gravity of piston parts, so as to eliminate the influence of gravity on resistance measurement. During the experiment, rotating the screw micrometer knob can pull the steel wire rope and tension sensor to move, and finally pull the support shaft of the support cylinder to move. The tension value that was fed back by the tension sensor is collected and set as the internal resistance of the support cylinder under the current displacement. A laser micrometer is used to directly measure the displacement of the piston shaft of the support oil cylinder in a non-contact manner. In order to ensure that the tension value of the tension sensor can truly reflect the internal resistance of the support cylinder, it is necessary to ensure that the tension sensor and the support shaft have good coaxiality as far as possible. The theoretical resistance and experimentally measured resistance of the support cylinder are shown in Figure 17.

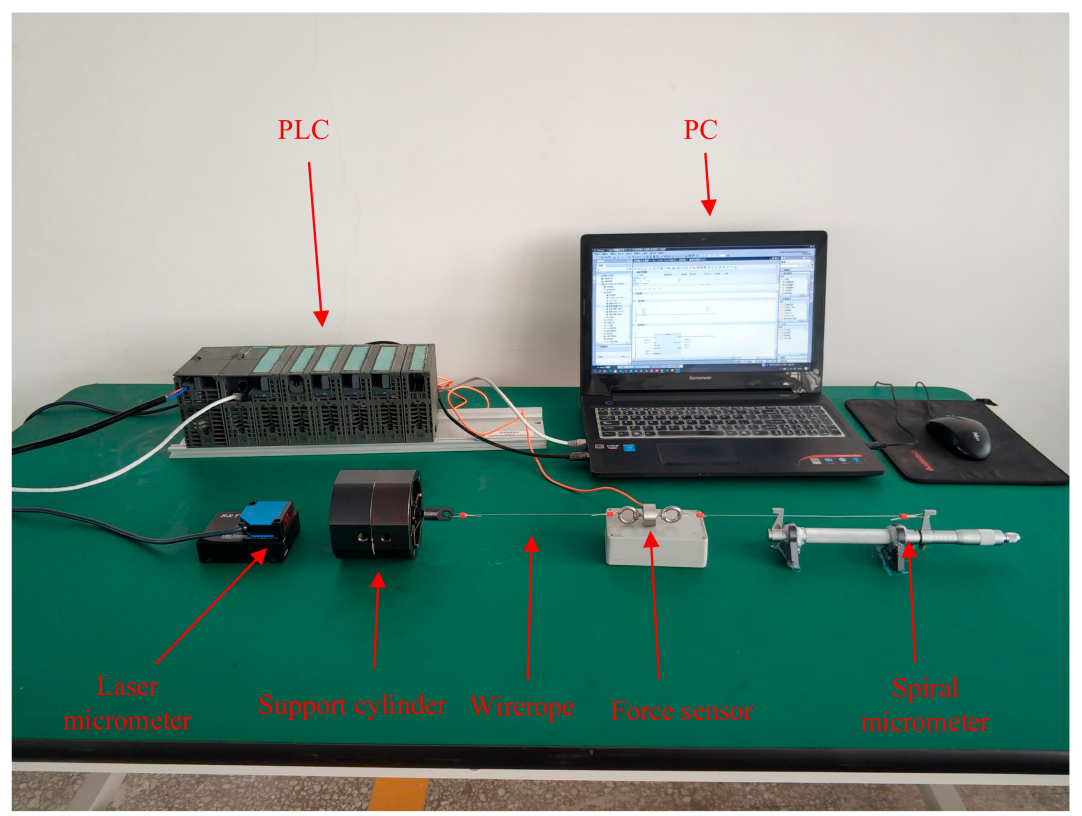

Figure 16. Internal resistance measurement test bench.

As shown in Figure 17, when the displacement of the support shaft is larger than zero, the deformation resistance generated by the BBR and RD causes the internal resistance of the support cylinder to increase. There is an error of approximately $0.4 \mathrm{~N}$ between the actual measured resistance and theoretical resistance. It is within the permissible range of error. The main cause of the error is the variation in the local elastic modulus caused by thermal deformation and thermal deterioration when the BBR is cut online. The experimental results verify the accuracy and effectiveness of the established mathematical models of $\mathrm{BBR}$ and RD deformation resistance. These also demonstrate that the optimization of multiobjective parameters can effectively reduce the internal resistance of support cylinders. 


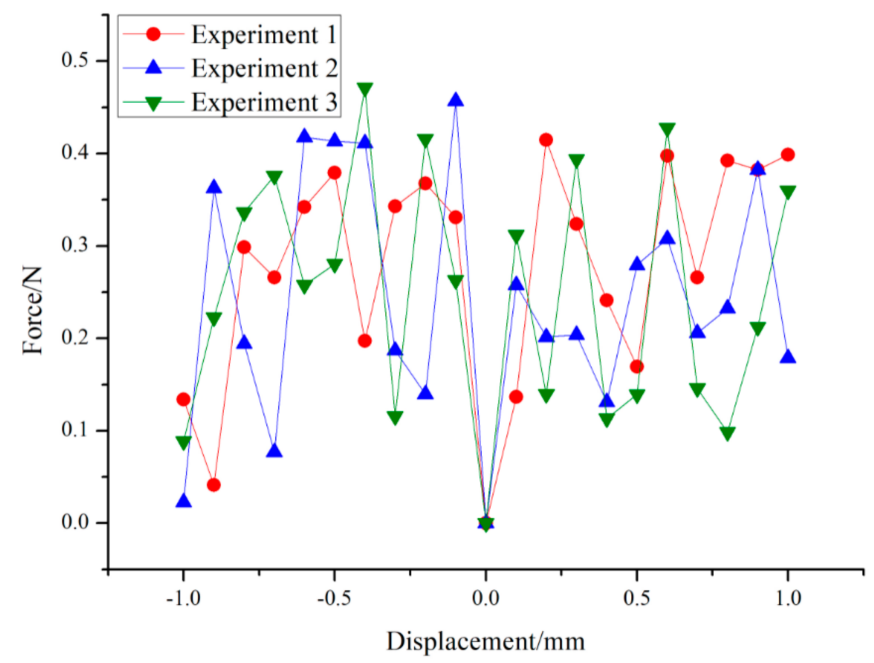

Figure 17. Internal resistance measurement experiment.

\subsection{Force Output Consistency Experiment}

The consistency of force output is an important performance parameter of FSSs. The difference between the maximum and minimum force output should not exceed $1 \mathrm{~N}$. The force output consistency is the degree to which the optical mirror gravity can be distributed uniformly on each support shaft of the FSS. When the support cylinder is arranged uniformly on the support floor and the pressure of the FSS is equal, the force output consistency is directly affected mainly by the internal resistance of the support cylinder. During the experiment, a load-bearing sensor is installed on the support shaft, and the optical mirror with a diameter of $1280 \mathrm{~mm}$ and a weight of $43 \mathrm{Kg}$ is placed on the FSS. Then, the pressure of the FSS is increased to $0.5 \mathrm{MPa}$, and the output force of each support shaft is measured by reading the feedback value of the sensor.

As shown in Figure 18, the experiment on the FSS is repeated three times. The black curve is the theoretical output value, and the remaining are the measured force output values. An analysis of the collected data reveals that the difference between the maximum and minimum values of force output in the three experiments are $0.87 \mathrm{~N}, 0.93 \mathrm{~N}$, and $0.77 \mathrm{~N}$, respectively. These are less than the limit range of $1 \mathrm{~N}$. That is, the designed FSS satisfies the requirements of force output consistency. It can be seen that the designed FSS is suitable for large optical mirror support with a diameter of more than $1000 \mathrm{~mm}$ and a total weight of less than $360 \mathrm{Kg}$.

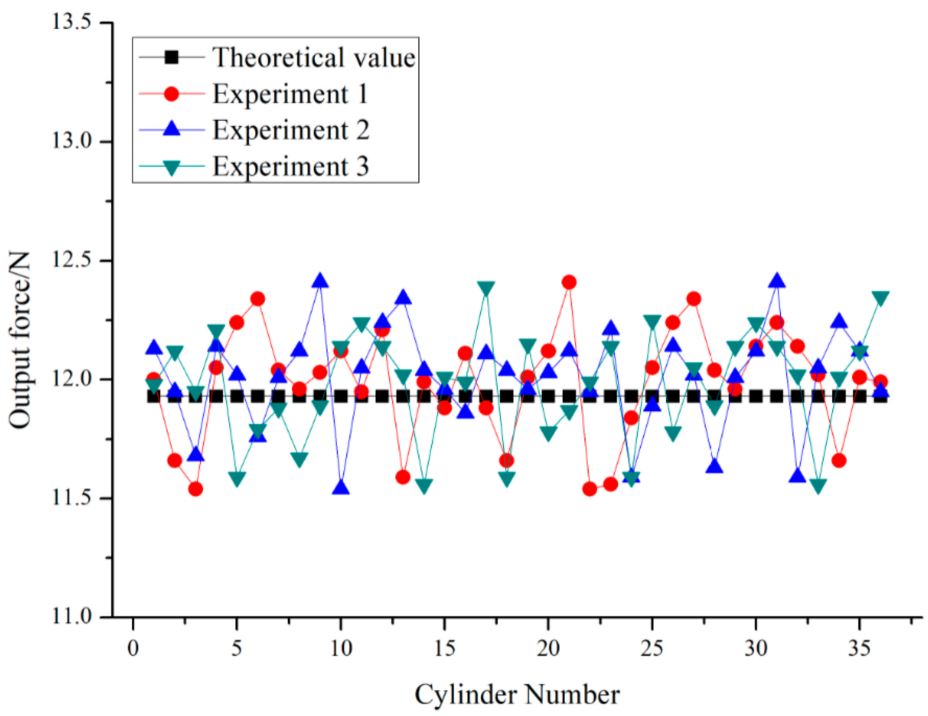

Figure 18. Force output consistency experiment. 


\section{Conclusions}

An FSS with adjustable stiffness and unloading impact of the tool on the mirror surface to be processed is designed to improve the processing precision of optical mirrors. The movement resistance of the support cylinder is established to study the axial movement resistance of the FSS. The main factors affecting the movement resistance are the deformation resistance of the BBR and RD. To minimize the motion resistance of the support cylinder and improve its force output consistency, a multi-object parameters deformation resistance model of BBR and RD is established and its structural parameters optimized. The established model is simulated and analyzed in ANSYS. The force required to deform the BBR by $1 \mathrm{~mm}$ in the positive or negative $Y$-direction, force required to deform it by $0.5 \mathrm{~mm}$ in the positive $X$-direction, deformation caused by the application of a force of $1 \mathrm{~N}$ in the positive or negative $Y$-direction, and deformation caused by the application of a force of $10 \mathrm{~N}$ in the positive $X$-direction are calculated separately. In addition, the forces required by the RDs with different hardness values under different deformations are calculated by simulation. The simulation results are analyzed to obtain the optimal parameters for the BBR and RD that satisfy the performance requirements of the FSS.

A pressure test of the FSS, an internal resistance measurement experiment, and a force output consistency experiment are conducted to determine the effect of the BBR and RD optimized by multi-objective parameters on the performance parameters of the FSS. The experimental results show that the actual measurement and simulation analysis of the deformation of the RD and BBR require essentially an equal force. In addition, the maximum and minimum force output of the support shaft is less than the design limit of $1 \mathrm{~N}$. The optimized design of the FSS satisfies the adjustable support stiffness while effectively reducing the movement resistance and improving the force output consistency. This provides a theoretical basis for its application in the field of high-precision optical processing. The designed FSS can also be applied to the attitude adjustment of large optical mirrors, and similar engineering fields with high accuracy requirements are also the application object of this study.

Based on the results of this paper, the cooperative work between the FSS and the optical mirror machining robot can be applied to the whole process of optical mirror machining. The response of the support system in the dynamic environment is analyzed, in order to optimize the overall performance and further improve the surface accuracy of the optical mirror.

Author Contributions: Conceptualization, Z.J. and G.C.; methodology, Z.J.; software, Z.J.; validation, G.C., S.X. and D.Y.; formal analysis, Y.P.; investigation, S.X.; resources, G.C.; data curation, S.X.; writing-original draft preparation, Z.J.; writing—review and editing, Z.J.; visualization, G.C.; supervision, G.C.; project administration, G.C.; funding acquisition, G.C. All authors have read and agreed to the published version of the manuscript.

Funding: Financial support for this work, provided by the Priority Academic Program Development of Jiangsu Higher Education Institutions and the National Natural Science Foundation of China (Grant No. 91648105), are gratefully acknowledged.

Institutional Review Board Statement: This study does not involve humans or animals.

Informed Consent Statement: This study does not involve humans or animals.

Data Availability Statement: The simulation and experimental data used to support the findings.

Conflicts of Interest: The authors declare that there are no conflict of interest regarding the publication of this paper.

\section{References}

1. Lian, P.Y.; Wang, C.S.; Xue, S.; Xu, Q.; Shi, Y.; Jia, Y.; Xiang, B.; Wang, Y.; Yan, Y. Surface adjustment strategy for a large radio telescope with adjustable dual reflectors. IET Microw. Antennas Propag. 2019, 13, 2669-2677. [CrossRef]

2. Ma, D.L. Recommended conceptual optical system design for China's large optical-infrared telescope (LOT). Opt. Express 2018, 26, 108-119. [CrossRef] 
3. Tan, Y.F.; Wang, J.H.; Ren, G.; Xie, Z. Thermal control analysis of a primary mirror for large-aperture telescope. J. Korean Phys. Soc. 2017, 71, 28-36. [CrossRef]

4. Cheng, G.; Qiu, B.J.; Yang, D.H.; Liu, H. Workspace analysis of 3-CPS parallel micro-manipulator for mirror active adjusting platform. J. Mech. Sci. Technol. 2012, 27, 3805-3816. [CrossRef]

5. Liu, P.F.; Lin, B.; Zhang, X.F.; Li, Y. Fluid hydrodynamic fixed abrasive grinding based on a small tool. Appl. Opt. 2017, 56, 1453-1459. [CrossRef]

6. Kong, Y.X.; Cheng, G.; Guo, F.; Gu, W.; Zhang, L. Inertia matching analysis of a 5-DOF hybrid optical machining manipulator. J. Mech. Sci. Technol. 2019, 33, 4991-5002. [CrossRef]

7. Lan, B.; Wu, X.X.; Li, J.F.; Ming, M.; Liu, X.; Yang, H. Influence of axial-force errors on the deformation of the $4 \mathrm{~m}$ lightweight mirror and its correction. Appl. Opt. 2017, 56, 611-619. [CrossRef] [PubMed]

8. Su, D.Q.; Liang, M.; Yuan, X.Y.; Bai, H.; Cui, X. The optical system of the proposed Chinese 12-m optical/infrared telescope. Mon. Not. Roy. Astron. Soc. 2017, 469, 3792-3801. [CrossRef]

9. Arnold, L. Uniform-load and actuator influence functions of a thin or thick annular mirror: Application to active mirror support optimization. Appl. Opt. 1996, 35, 1095-1106. [CrossRef] [PubMed]

10. Li, J.S.; Liu, P.K. Dynamic analysis of 5-DOFs aerostatic spindles considering tilting motion with varying stiffness and damping of thrust bearings. J. Mech. Sci. Technol. 2019, 33, 5199-5207. [CrossRef]

11. Jin, Z.; Cheng, G.; Xu, S.; Gu, W. Dynamic Disturbance and Error Analysis of Flexible Support System for Large Optical Mirror Processing. Appl. Sci. 2021, 11, 2715. [CrossRef]

12. Li, B.; Zhao, H.Y.; Xi, J.P.; Ren, D.X. On-machine self-calibration method for compensation during precision fabrication of 900-mm-diameter zerodur aspheric mirror. Int. J. Adv. Manuf. Technol. 2015, 76, 1855-1863. [CrossRef]

13. Zhou, P.W.; Zhang, D.X.; Liu, G.; Yan, C. Development of space active optics for a whiffletree supported mirror. Appl. Opt. 2018, 58, 5740-5747. [CrossRef] [PubMed]

14. Kihm, H.; Yang, H.S.; Moon, I.K.; Yeon, J.H. Adjustable bipod flexures for mounting mirrors in a space telescope. Appl. Opt. 2012, 51, 7776-7783. [CrossRef]

15. Qiang, L.; Shuxin, W.; Fuxiang, T.; Jinguo, T. Research on integrated design method of high-precision space-based active optical large-caliber splicing mirror drive and support. Optik 2019, 204, 163849. [CrossRef]

16. Yang, L.; Wei, L.; Zhang, L. Thermal compensation design of truss structure for large-scale off-axis three-mirror space telescope. Opt. Eng. 2019, 58, 023109. [CrossRef]

17. Bi, S.S.; Yao, Y.B.; Zhao, S.S.; Yu, J. Modeling of cross-spring pivots subjected to generalized planar loads. Chin. J. Mech. Eng. 2012, 25, 1075-1085. [CrossRef]

18. Lei, W.; Lei, Z.; Gong, X.X.; Ma, D. Design and optimization for main support structure of a large-area off-axis three-mirror space camera. Appl. Opt. 2017, 56, 1094-1100.

19. Hu, H.F.; Luo, X.; Liu, Z.Y.; Zhang, X.; Xue, D.; Zhao, H. Designing a hydraulic support system for large monolithic mirror's precise in-situ testing-polishing iteration. Opt. Express 2019, 27, 3746-3760. [CrossRef]

20. Huo, T.; Yu, J.; Zhao, H. Design of a kinematic flexure mount for precision instruments based on stiffness characteristics of flexural pivot. Mech. Mach. Theory 2020, 150, 103868. [CrossRef]

21. Yan, G.; Bao, Z. Design and analysis for the flexible support structure of high precision lens assembly. Optik 2018, 175, 228-236.

22. Yu, F.; Xu, S. Flexible support structure based on spring principle for a high precision reflecting mirror. Optik 2020, $207,164341$. [CrossRef]

23. Dai, X.L.; Xian, H.; Tang, J.L.; Zhang, X.; Zhang, Y. Modification of the support and active correction method for an experimental thin primary mirror. J. Mod. Opt. 2019, 66, 1841-1849. [CrossRef]

24. Zhang, L.; Wang, W.; Wang, J.; Guo, P.; Hao, L. Design and analysis for the multi-point flexible support structure of large and precision lens. Optik 2019, 193, 162966. [CrossRef]

25. Wang, Z.S.; Zhang, J.X.; Wang, J.X.; He, X.; Liang, F.; Tian, F.; Liu, X.; Zhao, Y. A method based on exact constraint for supporting space-based large mirror with a diameter of $2.8 \mathrm{~m}$. Optik 2019, 179, 499-504. [CrossRef]

26. Bo, Q.L.; Liu, H.B.; Lian, M.; Liu, K. The influence of supporting force on machining stability during mirror milling of thin-walled parts. Int. J. Adv. Manuf. Technol. 2019, 101, 2341-2353. [CrossRef]

27. Bao, Y.; Kang, R.K.; Dong, Z.G.; Zhu, X.; Wang, C.; Guo, D. Multipoint support technology for mirror milling of aircraft skins. Mater. Manuf. Process. 2018, 33, 996-1002. [CrossRef] 